\title{
Preface to Special Issue
}

\author{
Benjaram M. Reddy ${ }^{1} \cdot$ Martin Muhler $^{2}$ \\ Published online: 14 November 2019 \\ (C) Springer Nature Switzerland AG 2019
}

We are pleased to bring out this special issue of Emission Control Science and Technology in honor of Professor Wolfgang Grünert on the occasion of his 70th birthday and in appreciation of his outstanding contributions to catalysis for over 40 years. Wolfgang was born on August 2, 1949, in Merseburg, Germany (then GDR). He studied chemistry as the main subject with focus on Industrial Chemistry at the Technical University Leuna-Merseburg from 1968 and obtained his $\mathrm{PhD}$ degree from the same university in 1975 on the research topic dealing with process intensification of chlorohydrin process for olefin oxides. Being disfavored for a university career due to his inelasticity towards the political establishment in GDR, he joined a research group at the GDR Academy of Sciences (Central Institute of Organic Chemistry, Leipzig branch). The focus of his early investigation was on aromatization with chromia-based catalysts, olefin metathesis over supported Mo- and W-based catalysts, naphtha reforming, and XPS characterization of catalysts. The latter was based on a long-standing cooperation with the late E. S. Shpiro from Zelinsky Institute of Organic Chemistry (then Soviet Academy of Sciences). After the opening of the GDR, he utilized the opportunities to work at the Fritz-Haber Institute of MaxPlanck Society in Berlin (1990/1991, with Prof. R. Schlögl, XPS/UPS/LEIS with zeolites) and with Prof. R. W. Joyner at Leverhulme Center of Innovative Catalysis Liverpool (1993, environmental catalysis). He completed his habilitation degree in 1992 at TU Leuna-Merseburg on the research work dealing with structure-activity relations in supported $\mathrm{Cr}$, Mo, and $\mathrm{W}$

Benjaram M. Reddy

bmreddy@iict.res.in

Martin Muhler

muhler@techem.rub.de

1 CSIR-Indian Institute of Chemical Technology, Hyderabad 500007 , India

2 Ruhr-Universität Bochum, 44780 Bochum, Germany catalysts. In 1994, he joined as a senior researcher at the Laboratory of Industrial Chemistry, Ruhr University Bochum, where he become full professor in 1997 and continued his entire career until his official retirement in 2016.

Wolfgang's entire research activities focussed on structureperformance relationships in heterogeneous catalysts, environmental catalysis (Selective Catalytic Reduction of $\mathrm{NO}$ with $\mathrm{NH}_{3}$ or hydrocarbons), $\mathrm{CO}$ oxidation, and three-way catalysis, test reactions for evaluation of $\mathrm{MoS}_{2} / \mathrm{WS}_{2}$ surfaces, fuel cells, surface analysis (XPS and LEIS), and X-ray absorption methods. His specific contributions to SCR and related topics include elucidation of active sites for hydrocarbon-SCR in Cu-ZSM-5 and Fe-ZSM-5, establishment that standard SCR and fast SCR proceeds on different sites on Fe zeolites, hybrid catalysts for $\mathrm{NH}_{3}-\mathrm{SCR}$, proposal of a new model for interaction of $\mathrm{V}$ and $\mathrm{W}$ in $\mathrm{TiO}_{2}$-supported catalysts for $\mathrm{NH}_{3}$-SCR, and so on. Wolfgang has authored or co-authored more than 200 papers published in international journals, as well as 9 patents. He has been serving as member of the Editorial Board of Applied Catalysis B: Environmental and Catalysis, Structure and Reactivity.

We believe that this special issue is a fine tribute to a creative researcher, outstanding teacher, cherished friend and colleague, and a wise man. Wolfgang, we congratulate you on a marvelous first 70 years and hope that you continue to do what you enjoy most for many years to come. We wish you excellent health and many more fruitful years of active research.

We would like to express our sincere gratitude to all the authors for their enthusiastic contributions and to the reviewers for their helpful and meticulous comments. Finally, we want to thank Springer and the Editors-in-Chief of Emission Control Science and Technology, Dr. Mansour Masoudi, Prof. Athanasios Konstandopoulos and the Editorial Staff, Ms. Sabine Malzkuhn particular, for their continuous help and support in bringing out this special issue successfully.

Publisher's Note Springer Nature remains neutral with regard to jurisdictional claims in published maps and institutional affiliations. 